SHS Web of Conferences 7, 01007 (2014)

DOI: $10.1051 /$ shsconf / 20140701007

C) Owned by the authors, published by EDP Sciences, 2014

\title{
Research and Application of Construction of Operation Integration for Smart Power Distribution and Consumption Based on "Integration of Marketing with Distribution"
}

\author{
Feng Zhenbao, Xu Genli, Zhang Yanbin \\ Jiaozuo Power Supply Corporation of Henan Power Company, 4541500 Jiaozuo Henan, China
}

\begin{abstract}
The "information integrated platform of marketing and distribution integration system" researched and developed by this article is an advanced application platform to concurrently design and develop the automation of marketing and power distribution through integration and analysis of existing data based on the data platform of Jiaozuo Power Supply Corporation. It uses data mining and data bus technology, uniform analysis of comprehensive marketing and distribution data. And it conducts a real time monitoring on power utilization information for marketing and early warning maintenance business of power distribution according to electric business model, which realizes an integration of marketing and distribution business, achieves the target of integrated operation of marketing and distribution, improves the operation level of business, reduces maintenance costs of distribution grid, increases electricity sales of distribution grid and provide reliable practical basis for operation and maintenance of Jiaozuo power marketing and distribution.
\end{abstract}

Keywords. integration of marketing and distribution; integration platform of information; smart distribution grid; power distribution and consumption

\section{Introduction}

Currently, smart power grid has become a worldwide hot spot of research in power industry. According to the actual condition of domestic power grid, State Grid proposed "strong smart power grid" concept. Construction of strong smart power grid requires the conformation of ripe technical support system, including smart power distribution and consumption system in the mode of smart power grid. Furthermore, the distribution grid is a user-oriented window of power energy application, and also an important component of smart power grid, as well as a vital breakthrough of intellectualization. For distribution grid directly connects to terminal users, the development of smart power distribution technology affects the personal interests of terminal users. Meanwhile, the good interactivity of smart power grid will make the development of smart power distribution technology affected by smart power consumption response action of users.

Based on the data provided by data platform of Jiaozuo Power Supply Corporation, this article performs a series of construction work of smart power grid, such as construction of integrated power grid regulation, smart converting station, power consumption information collection, etc.. This article uses modern information technology to improve the power supply reliability of distribution grid as the basis, and conduct research and design through compensation of reactive power optimization, line-loss 
reduction, maintenance efficiency improvement and interruption duration reduction, for the purpose of finally meeting the power supply quality, improving the target of user experience and realize the systematic connotation of integrated marketing and distribution, as well as system interaction and integration.

\section{Relevant researches}

Smart power grid has become a worldwide hot spot of research in power industry[1-8]. The combined pressures of resources and environment bring the global power industry into an era of smart power grid. The core of intellectualizing the power grid is to comprehensively and dynamically integrate customer-side resources, including relevant information used by loads and power [9]. Currently, the relevant research of smart power grid mainly focuses on four aspects [10]: Advanced Metering Infrastructure (AMI), Advanced Distribution Operation (ADO), Advanced Transmission Operation (ATO)and Advanced Assets Management (AAM). The international emphasis of research on smart power grid is varied, but more focus lies on issues related to power distribution and consumption.

The distribution grid directly connects to users, and the development of power distribution technology is related to personal interests for millions of users. On one hand, the development of modern industry has an increasingly higher demands on improvement of power supply reliability and power energy quality, such as precision test instrument, communication, etc., and on the other hand, the rapid development of distributed power generation (such as power generation by photovoltaic, wind power, biomass energy, fuel cell, etc.) requires the power distribution technology to possess the following features: fast regeneration of network, accessibility of Distributed Electric Resource, high anti-disturbance capacity, ability to provide quality electrical power, interaction with users, etc.. Construction of "customer-centered" smart power distribution system has an important guiding significance to achieve the target of realizing reasonable power consumption, conserving energy and reducing emission. With the promotion and application of new technologies such as electric vehicle, smart equipment, smart household appliances, smart construction, etc., the current power distribution plan and design mode will be changed. In the smart distribution grid, the demand-side management is a closely-related part. Promotion of demand-side management technology, such as smart instrument, communication, control system and other load control technology, is one of the key factors that determine whether the smart power grid will succeed in the future[11].

At present, the key technologies and project of demand-side management are generally divided into[12]: Energy Efficiency, Energy Conservation and Demand Response (DR). Smart Distribution Grid (SDG) features great amount of new technologies and huge difference from traditional power distribution technology, and has a decisive position in smart grid [13]. Currently, there is not an agreed definition of SDG and description of its functions, and it mainly has the features of: optimization of distribution grid assets, distributed energy grid connection, large-scale application of sensors and smart ammeter, ability of users to dynamically engage in demand response, possession of adaptation and self-regeneration technology, advanced equipment, integration of terminal power consumption units and smart power consumption equipment, as well as island running. One of the targets for the development of smart distribution grid is to solve the operative problems of a lot of Distributed Electric Resource scattered in distribution grid. In the research related to smart distribution grid, there are many researches on Distributed Electric Resource (DER). The DER grid connection mainly includes Distributed Storage DS) and Renewable Energy Sources (RES).

In general, SDG shall possess the following features[14-18]: high self-regeneration, security, power energy quality, user participation rate, assets availability, informationization, and supporting the access of large amount of distributed energy, etc..

\section{System design}

This system mainly researches the service integration demand between marketing and distribution grid and system structure to meet this demand; also the key technologies of failure detection and position 
technology, distribution grid communication network technology, power supply technology of frontend collection equipment, distribution transformer monitoring technology and distribution grid SVG technology, etc. which are related to smart operation of distribution grid, as well as other application patterns; It develops data metering, collection, compensation equipment, etc. according to research findings to further develop a corresponding integration platform of smart operation of distribution grid to realize the scientific, reasonable and utility purpose based on "integration of marketing and distribution". On the basis of GIS system, it connects the marketing and distribution system to uniformly integrate the power grid equipment and information model of electric power user with relevant data, which realizes many functions such as power failure management for users, line-loss management, construction planning of distribution grid, aid decision making, etc..

This system, depending on the existing data center of Jiaozuo Power Supply Corporation, mainly includes marketing management system, PMS, OMS, city-county dispatch data platform and GIS system, and can at the same time search for dispatch, biotech, branch letter and marketing information, etc. to ensure the high security, efficiency and convenience of operation of distribution grid.

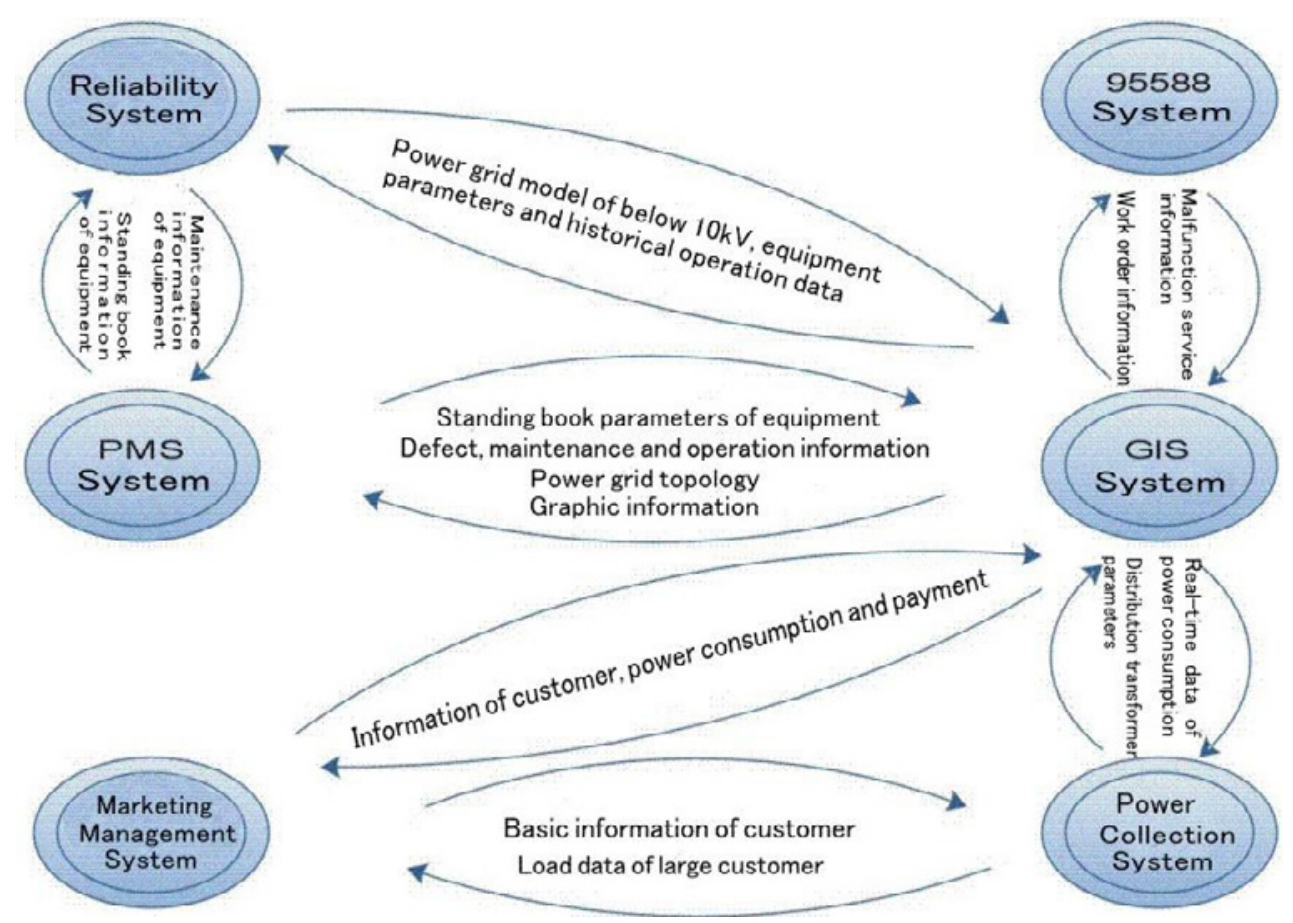

Figure 1. System design of operation integration for smart distribution grid based on integration of marketing and distribution.

The general design of integrated platform of system of operation integration for smart distribution grid based on integration of marketing and distribution complies to the public information model standard CIM and GID of IEC61970 and IEC61968 to normatively define the interface, and provide the interface, functional package, transformation and integration to each business application for distribution grid using object-oriented method to meet the requirement of real-time data exchange, and meanwhile construct the distribution grid service center and uniformly provide external basic business service. It provides a flexible basic connection framework for each business system of power industry. And through the integration of enterprise service, it can conveniently and rapidly share the information among marketing, 95588, PMS, etc., which efficiently settle the communication redundancy among each system, not only conducive to uniform management of data among each system in city-county distribution grid, but also meeting the actual need of production management of each department. 


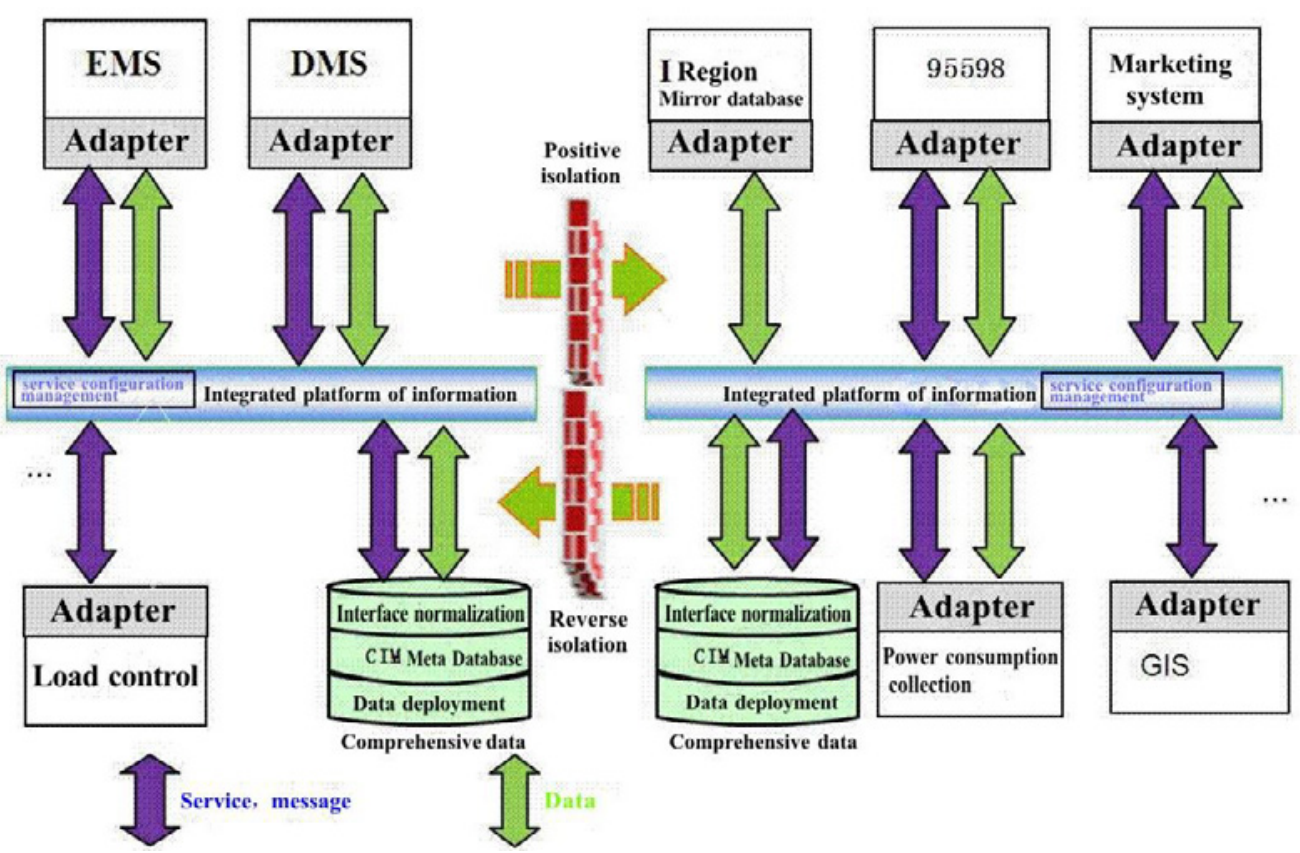

Figure 2. General framework of integrated platform of operation integration for smart distribution grid based on integration of marketing and distribution.

\subsection{Enterprise service bus}

There are many applications in distribution grid, and the data type and transmission protocol of them are diversified. By enterprise service bus, it provides many service functions such as communication service, dynamic routing service, data format analysis and transformation service, service register and search, safety control, data cache, abnormality treatment, log record, etc., and depends on real-time data exchange platform to normalize the integrated standard and interface, thus to realize the collaborative management and service. The integration functions of enterprise service bus are as follows:

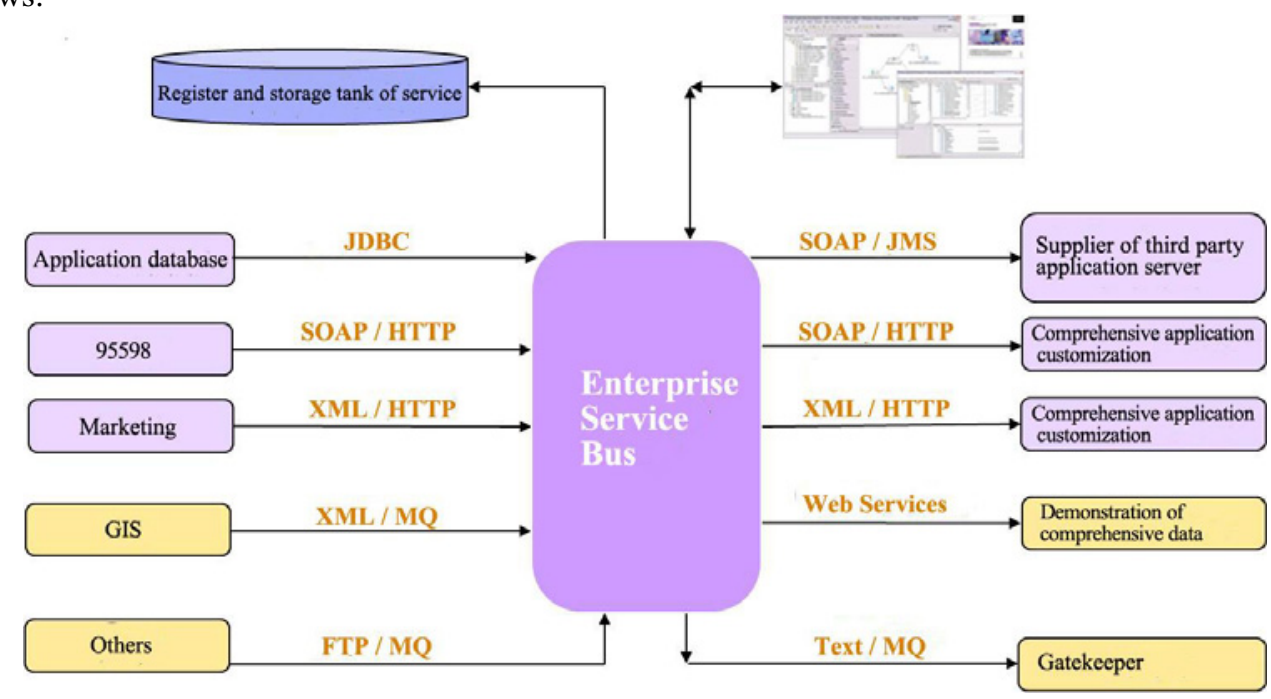

Figure 3. Building-block of logic of system of operation integration for smart distribution grid based on integration of marketing and distribution. 


\subsection{Information integration bus}

The information integration bus mode is based on management of Meta Data, and supports exchange and integration of bulk data by the consistency, continuity and comprehensiveness of Meta Data, which realizes centralized and efficient management for different data. Its framework is as follows:
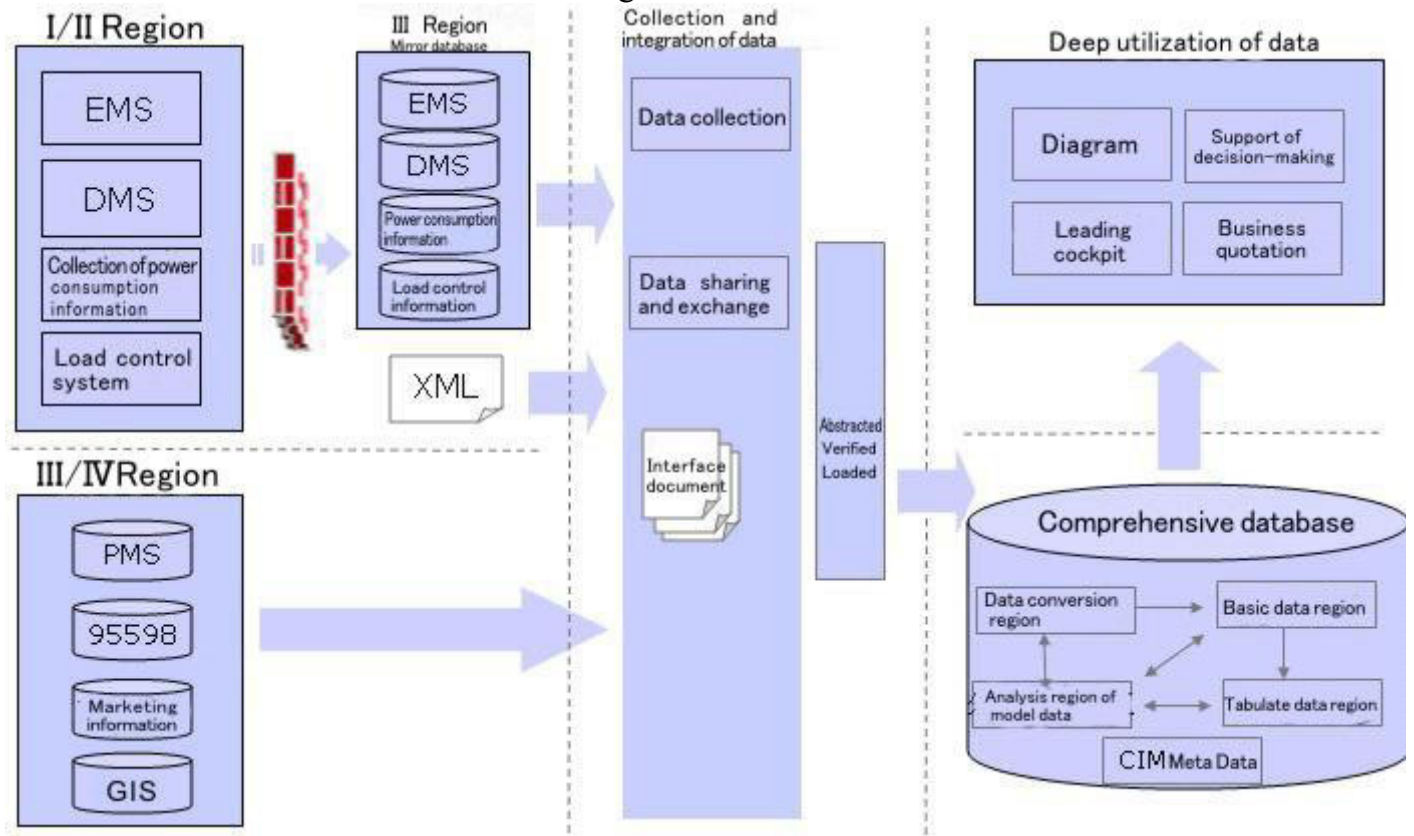

Figure 4. Data flow diagram of system of operation integration for smart distribution grid based on integration of marketing and distribution.

In the information integration platform of distribution grid, the objects required to access based on data integration module mainly include:

\section{Business system information in I/II region}

In consideration of security, the physical isolation units are set in the business system information in I/II region, which prevents the direct access to the system information. However, most of the information can be accessed through mirror database in III region. Therefore, the accessibility to the business system information in I/II region by searching of the mirror database satisfies the information integration requirements. For minor information inaccessible in the mirror database can be accessed by uploading and downloading the documents. The main objects include:

(1)EMS system: Power grid model of above $10 \mathrm{kV}$, equipment parameters and historical operation data;

(2)Load control system: direct supply of users, load information of power plant and historical data;

(3)Automation system of power distribution: historical information of distribution grid regulation;

(4) Power consumption information collection system (distribution transformer monitoring system): distribution transformer parameters and historical data.

\section{Business system information in III region}

The information integration bus of integrated platform can directly abstract data objects from relevant business system in III region to realize the integration of relevant business data. It mainly includes:

(1)PMS data: standing book information of equipment and historical production data;

(2) 95598 malfunction service data: historical malfunction service and work order information;

(3) Marketing management information: information of customer, power consumption and payment; 
(4) GIS topological information: power grid model of above $10 \mathrm{kV}$, equipment parameters and historical operation data.

\section{Conclusion}

To efficiently integrate the marketing management information with distribution grid production management information, the work and demonstration are conducted uniformly in the platform to realize the interflow and share of information for both, and thus to reduce internal consumption of distribution grid, increase the operation and management level of electrical power system and strengthen the core competitiveness of electrical power system. The realization of this system reduces the line-losses, increases the power consumption quality for customer, conserves the time of breakdown rescue and creates a great social benefit.

\section{References}

1. Liang Hongjian, Huang Yingqi. Brief Discussion on Application and Development of Dispatch Automation in Power Grid Project[J]. Guangdong Science and Technology, 2007(11):169-170.

2. Eleventh Five-Year Plan Science and Technology Development Program Planning for Rural Power Grid Proposed by State Grid Corporation[S].

3. Technical Directives of Automation and Communication System for Rural Power Grid Proposed by State Grid Corporation[S].

4. Xi Guofu, Wu Fubao, Zhu Jinda. Development Trend of Integration System Technology of County-Level Power Grid Allocation[J]. Electrical Equipment, 2006, 7(6):13-16.

5. Xin Yaozhong. Development Trend of New Century Grid Dispatch Automation Technology[J]. Power Grid Technology, 2001, 25(12):1-10.

6. Han Zhenxiang, Qiu Jiaju, etc.. Power System Analysis (2nd Edition)[M]. Zhejiang: Zhejiang University Press, 1997.

7. Jin Longzhang, Ding Shushan. SVG Utility Technology for State Grid (1st Edition) [M]. Beijing: Chinese Water Conservancy and Hydropower Press, 1997.

8. Yu Erkeng, Liu Guangyi, Zhou Jingyang, etc.. Energy Management System(EMS) (1st Edition) [M]. Beijing: Science Press, 1998.

9. Xie Xiren, Computer Network(3rd Edition), Dalian: Dalian University of Technology Press, 2000.

10. Ma Weixin. Power System Voltage (1st Edition) [M]. Beijing: Chinese Power Press, 1998.

11. Shen Shuming. Automation System for Power Grid SCADA / EMS / DMS / MIS in the New Generation of Areas[J]. Electric Power Automation Equipment, 2001, 21(1):47-48.

12. Huang Wei, Zhang Jieming, etc. Solutions of Management and Alarm in Responsibility Area for System Integrated with Dispatch and Centralized Control[J]. Power Grid Technology, 2007, 31(2):264-267.

13. Zhou Zhiquan. Lamination of Automation Information for Power Grid Dispatch[J]. Automation of Electric Power Systems, 1999(22).

14. Wang Mingjun, Fu Shuyi, Wu Yusheng. Management System of Opening Energy Designed for Object Orientation[M]. Beijing: Chinese Power Press, 1997.

15. Wu Yiwen, Huang Yizhuang, Integration Of Data with Graphic in Dispatch Automation System[J]. Automation of Electric Power Systems, 2000(24):52-54, 64.

16. Gao Mingyan, Lu Wen. Platform Construction Technology of Power Grid SCADA / EMS / DMs[J]. Automation of Electric Power Systems, 1999 (14):41-44.

17. Cai Yang. Power Grid Dispatch Automation with New Requirements, Development and Facing New Century[J]. Automation of Electric Power Systems, 1998(12).

18. L. Hano, Y Tamura, S. Narita, K. Matsumoto. Real Time Control of System Voltage and Reactive Power[J]. TEEE Trans on Power Apparatus \& Systems, 1969,10:1544-1559. 